\title{
Investigation of commercial ready-mixed mortars for architectural heritage
}

\author{
D. Gulotta ${ }^{1}$, L. Toniolo ${ }^{1}$, L. Binda ${ }^{2}$, C. Tedeschi ${ }^{2}$, \\ R. P. J. van Hees ${ }^{3,4} \&$ T. G. Nijland ${ }^{3}$ \\ ${ }^{I}$ Politecnico di Milano - Dipartimento di Chimica, \\ Materiali e Ingegneria Chimica "Giulio Natta", Italy \\ ${ }^{2}$ Politecnico di Milano - Dipartimento di Ingegneria Strutturale, Italy \\ ${ }^{3}$ TNO Built Environment and Geosciences, The Netherlands \\ ${ }^{4}$ Departement RMIT, Faculty of Architecture, \\ Delft University of Technology, The Netherlands
}

\begin{abstract}
In conservation practice, operations aiming to restore structural functionality of historical buildings are of primary relevance. Partial rebuilding, the substitution of damaged bricks or blocks and the integration of deteriorated joints are, among others, interventions that require the introduction of new materials in a heterogeneous and aged masonry system. An appropriate durability of these interventions can only be assured if a deep knowledge of the original materials and of their state of conservation is combined with reliable understanding of the behaviour of new materials introduced. The present paper reports the results of the investigation of four commercial ready-mixed mortars based on NHL binders. The mineralogical composition of each product has been evaluated by XRD and polarization-and-fluorescence microscopy (PFM). The molecular composition of the mixes has also been evaluated by FTIR spectroscopy and the morphological features have been studied by SEM observations. The mechanical behaviour has been tested as well. Although supposedly comparable products, the mortars show different compositional features, microstructures, additives and mechanical behaviour. These are essential to evaluate compatibility with historic materials, and should be stated on the technical data sheets, or be determined.
\end{abstract}

Keywords: ready-mixed mortars, mortar characterization, natural hydraulic lime, XRD, FTIR. 


\section{Introduction}

A number of ready-mixed mortars designed for restoration purposes are currently available on the market and their use in the conservation field is increasing. The diffusion of such products is mainly related to their ease of use, which also determines a higher cost in respect to a manually prepared traditional mortar mix. Ready-mixed mortars are available as packed powder material composed of binder, aggregates of different nature and granulometry and additives already mixed together in appropriate ratios. Technical data sheets state the correct amount of water to be added and often supply indications about mixing procedure. In such a way, mortar preparation is clearly a quick operation compared to the traditional method and requires a low level of labour specialization.

Natural hydraulic lime is one of the most common binders used in commercial mixes for restoration. Technical standard UNI EN 459-1 [1] gives a definition for NHL (natural hydraulic lime) based on raw materials, production process and final behaviour. Natural hydraulic lime results from the burning of argillaceous or siliceous limestone, followed by reduction to powder by slaking, with or without grinding. NHLs are able to set and harden even under water and atmospheric carbon dioxide contributes to the hardening process. The burning temperature is kept below the clinkering point so that dicalcium silicate $\left(\mathrm{C}_{2} \mathrm{~S}\right)$ is the dominant hydraulic phase together with some gehlenite $\left(\mathrm{C}_{2} \mathrm{AS}\right)$ and only trace of highly reactive tricalcium silicate $\left(\mathrm{C}_{3} \mathrm{~S}\right)$, typical of Portland cement [2]. Despite the increasing diffusion of NHL based ready-mixed mortars, a thorough characterisation of commercial products is rarely available. Several studies have been conducted in the past aimed to develop methodologies for the characterization of ancient mortars, in some case with a particular interest to the new material introduced during restoration operations [3]. Recent studies have been also focused on characterisation of some XIX and XX century mortars. Methodologies have been defined in order to identify the nature of binders and to distinguish between natural hydraulic mortars, natural cements and Portland cements $[4,5]$. FTIR, XRD analysis and SEM observation have been employed to identify gehlenite and $\mathrm{C}_{3} \mathrm{~S}$, as characteristic hydraulic phase respectively of natural hydraulic lime and cements.

Materials used in the conservation field must fulfil special requirements in order to be compatible with the original materials [6]. The clear lack of information about commercial ready-mixed mortars' composition, however, does not allow a choice of suitable restoration materials based upon the evaluation of their compatibility.

The present work proposes a methodology for the characterization of readymixed mortars and reports on some results of its application on four diffused commercial products. Compositional, morphological and mechanical features are discussed and compared. 


\section{Experimental}

\subsection{Products and supplier}

Four ready-mixed commercial mortars, designed for restoration purposes and all classified as cement-free, with a minimum content of soluble salts and based on NHL - a natural hydraulic lime binder - were selected. The sample materials have been named MA, MB, MC and MD without any reference to the supplier.

\subsection{Specimens preparation}

Mortars were prepared according to the indication reported in the technical data sheets. Casting was performed following two different procedures: traditional casting in $4 \times 4 \times 16 \mathrm{~cm}$ demountable steel mould and by using a porous substrate. The porous substrate for the latter type of specimen was provided by fire-clayed brick, type "San Marco". Bricks underwent a 12-hours water imbibition followed by gently wiping of the surface to remove the layer of liquid water before mortars application. Specimens were let to harden for 48 hours at $20^{\circ} \mathrm{C}-90 \%$ RH. Specimens prepared following traditional casting were then removed from the mould, while specimens prepared on porous substrate were stored just as they were together with their brick substrates. The curing conditions were $20^{\circ} \mathrm{C}-90 \%$ RH for 60 days for specimens on porous substrate and for 28 and 60 days for traditional prismatic specimens.

\subsection{Analytical techniques}

The initial composition of the mortar mixture was analyzed by X-ray diffraction and IR spectroscopy on anhydrous powder samples. X-ray diffraction was carried out by means of a Philips PW1830 instrument using $\mathrm{Cu}$ K $\alpha$ radiation $(\lambda=$ 1,54058 Á). FTIR spectroscopy was carried out on a Thermo Nicolet 6700 instrument coupled with a FTIR Continum microscope. Fine grinded samples were analysed as KBr pellets (KBr FTIR grade by Sigma-Aldrich).

Mechanical behaviour of hardened mortars was studied on traditional $4 \times 4 \times 16$ $\mathrm{cm}$ specimens while the observation of the microstructural features was made on specimens prepared on porous substrate.

Compressive strength was evaluated after a curing time of 28 days and 60 days, according to standard protocol [6]. Five specimens were tested for each mortar and the reported results are average values from 5 different measurements.

Preliminary observation of the microstructure of the mortars was made with a Leica M205C stereomicroscope, equipped with a Leica DFC290 digital camera. Polarization-and-fluorescence microscopy was performed on thin sections, vacuum impregnated with a UV-fluorescent resin, using a Zeiss Axioplan microscope. Further microstructural characterization was performed by scanning electron microscopy on freshly fractured samples. An Environmental Scanning Electron Microscope (ESEM) Zeiss EVO 50 EP equipped with an Oxford INCA 200 - Pentafet LZ4 spectrometer was used in secondary electrons mode. 


\section{Results}

\subsection{XRD analysis}

Results of XRD analysis of anhydrous powder samples of mortars are summarised in table 1.

Results show significant differences in the binder and aggregate composition for the four examined mortars. Mortar MA is the only one showing characteristic peaks of portlandite, $\mathrm{Ca}(\mathrm{OH})_{2}$, while in all other cases the presence of larnite $\left(\mathrm{Ca}_{2} \mathrm{SiO}_{4}\right.$, i.e. an analogue of $\left.\mathrm{C}_{2} \mathrm{~S}\right)$ in the binder composition confirms the hydraulic behaviour of the mortar. The presence of gypsum can be observed as traces in mortar MD and in higher amount in mortar MB. All mortars contain calcite and quartz as aggregates, in different ratios. MA and MB also contain micas and plagioclase, MC and MD aggregate is partially composed of dolomite.

The diffractograms reported in fig. 1 highlight the abundance variability of the crystalline phases of the four analysed mixes.

\subsection{FTIR analysis}

MC and MD spectra are quite similar; the absorption peaks indicating that a large amount of carbonates are present, calcite $\left(1420,875,713 \mathrm{~cm}^{-1}\right)$ in $\mathrm{MC}$, dolomite $\left(1420,880,729 \mathrm{~cm}^{-1}\right)$ in MD sample. MC contains also a significant amount of free portlandite $\left(\mathrm{Ca}(\mathrm{OH})_{2}\right)$, with a sharp peak at $4643 \mathrm{~cm}^{-1}$. Si-O and $\mathrm{Si}-\mathrm{O}-\mathrm{Si}$ bonds vibrational modes are detectable in the range of frequencies between 1100-750 [5]: quartz around $1080 \mathrm{~cm}^{-1}$ with a characteristic doublet at 797 and $779 \mathrm{~cm}^{-1}$; calcium silicates at $1000-1010 \mathrm{~cm}^{-1}$ and $930 \mathrm{~cm}^{-1}$; pozzolan or other poorly crystalline siliceous phases giving a broad peak around 1035-1030 $\mathrm{cm}^{-1}$. Peaks related to the presence of quartz can be detected in both samples, while some peaks related to the presence of calcium silicates are detected only in sample MC.

MB sample contains calcite and portlandite, similar to the samples discussed above. However, more absorption occurs in the region of $\mathrm{Si}-\mathrm{O}$ peaks, where quartz $\left(1093 \mathrm{~cm}^{-1}\right)$ and pozzolan $\left(1033 \mathrm{~cm}^{-1}\right)$ peaks are detected. Finally, MA sample shows a quite different vibrational spectrum in the mid-IR region. The aggregate fraction is mainly composed of quartz $\left(1082,797,779 \mathrm{~cm}^{-1}\right)$ and

Table 1: $\quad$ Results of XRD analysis on dry powder samples. $\mathrm{P}=$ portlandite; $\mathrm{L}=$ larnite; $\mathrm{G}=$ gypsum; $\mathrm{A}=$ albite; $\mathrm{C}=$ calcite; $\mathrm{D}=$ dolomite; $\mathrm{K}$ = kyanite; $\mathrm{M}=$ muscovite; $\mathrm{Q}=$ quartz.

\begin{tabular}{|c|c|c|c|c|c|c|c|c|c|}
\hline & P & L & G & A & C & D & K & M & Q \\
\hline MA & $\checkmark$ & - & - & $\checkmark$ & $\checkmark$ & - & $\checkmark$ & $\checkmark$ & $\checkmark$ \\
\hline MB & - & $\checkmark$ & $\checkmark$ & $\checkmark$ & $\checkmark$ & - & - & $\checkmark$ & $\checkmark$ \\
\hline MC & - & $\checkmark$ & - & - & $\checkmark$ & $\checkmark$ & - & - & $\checkmark$ \\
\hline MD & - & $\checkmark$ & $\checkmark$ & - & $\checkmark$ & $\checkmark$ & - & - & $\checkmark$ \\
\hline
\end{tabular}




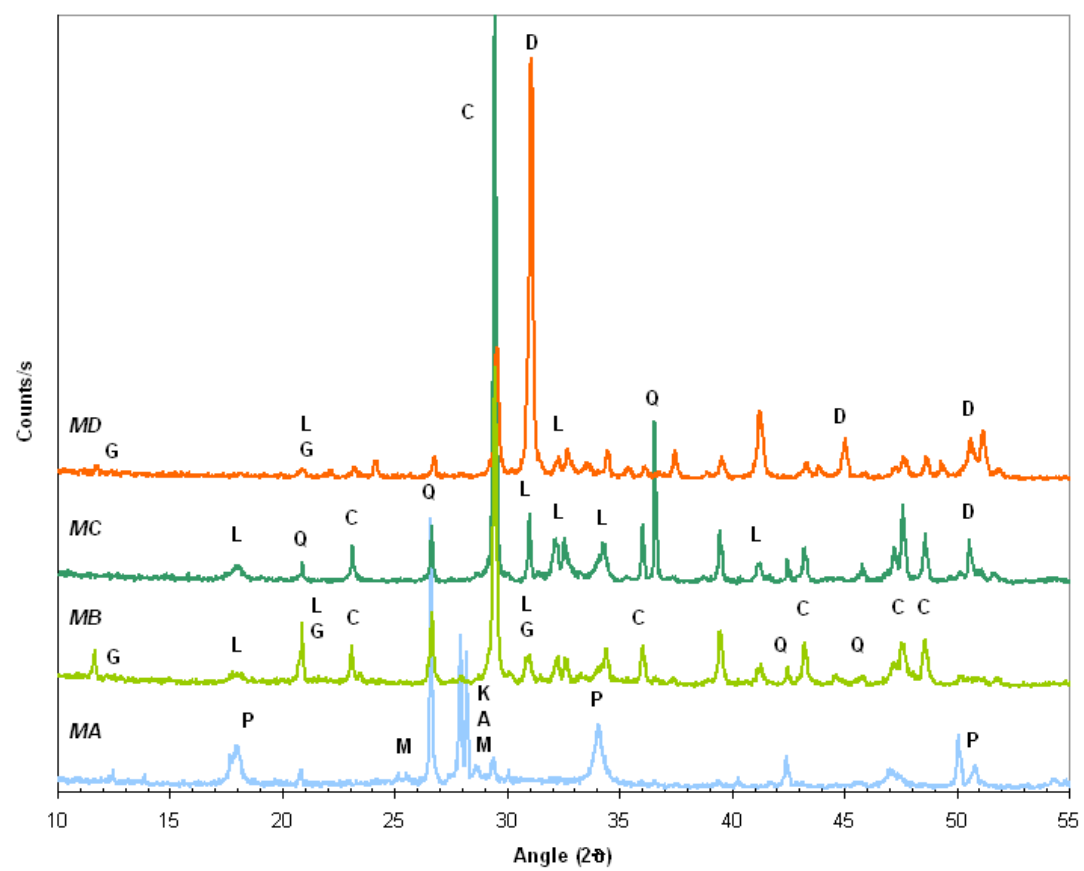

Figure 1: X-ray diffractograms of dry powder samples of the four studied mortars.

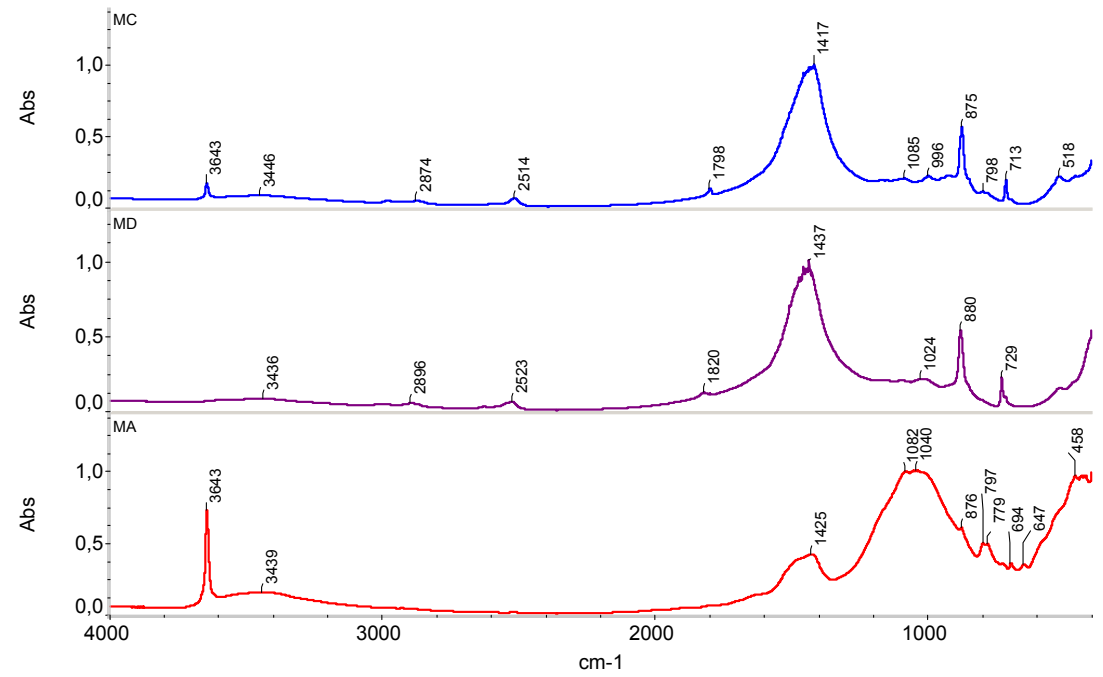

Figure 2: $\quad$ FTIR spectra of MC (upper one), MD (middle one) and MA (lower one) samples in the spectral range $4000-400 \mathrm{~cm}^{-1}$. 
calcite $\left(1425,876 \mathrm{~cm}^{-1}\right)$, while a very intense peak at $3643 \mathrm{~cm}^{-1}$ indicates the abundant presence of portlandite. The broad overlapped absorption peak around $1040 \mathrm{~cm}^{-1}$ could indicate again the presence of hydraulic silicates, probably slag (see below).

\subsection{Petrography}

Thin sections observations were carried out on specimens prepared on brick surfaces in order to consider the influence of the porous substrate on the microstructure of hardened mortar.

Mortar MA is composed of a hydraulic lime binder with irregular porosity. No cracks or fractures are present; the mortar matrix shows a quite compact microstructure with a fine grained binder.

Aggregates are poorly sorted and vary in size up to $2 \mathrm{~mm}$. Quartz is the most common aggregate, with rounded shape. Limestone, calcite, feldspar, plagioclase and rare amphibolites are also present. Limestone is generally present as coarse, rounded-shape aggregate while angular calcite grains are smaller in size. The very high amount of fine grained calcite crystals indicates that calcite has been used as a filler. A few small grains of pozzolan are also present.

The hydraulic phases of the binder are uniformly dispersed within the binder matrix. Few grains of not reacted $\mathrm{C}_{2} \mathrm{~S}$ are detected. A carbonation front proceeds from the margins into the bulk, with some isolated carbonated patches at deeper levels, along pores.
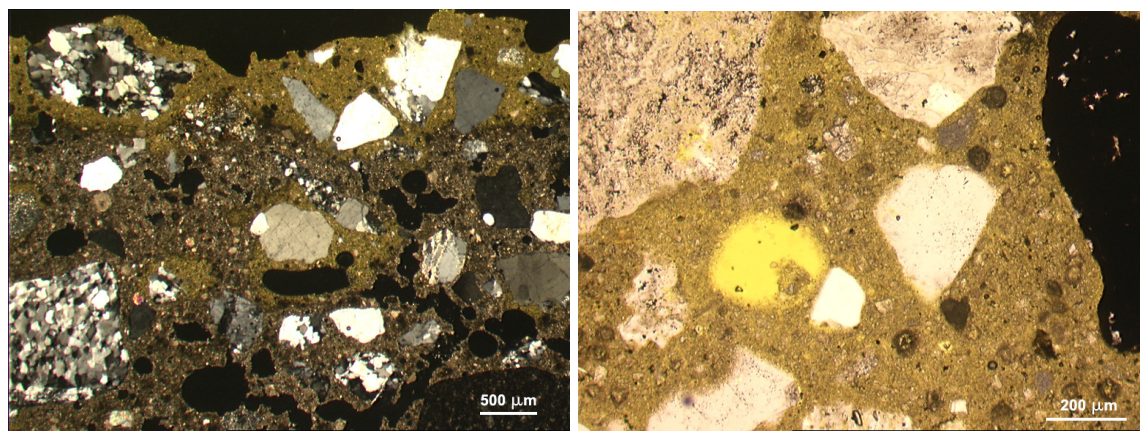

Figure 3: $\quad$ Mortar MA: carbonation front and irregular porosity (left, CPL); not reacted $\mathrm{C}_{2} \mathrm{~S}$ particles dispersed in the carbonated binder matrix (right, PPL).

Mortar MB has a completely different binder structure respect to the others. Porosity is irregular and lower than observed in mortar MA. Pores and voids of different shape are connected by a network of micro-cracks. Cracks occur both in the binder matrix and along the binder-aggregate interface.

Aggregates are heterogeneous; quartz is the main constituent, together with calcite, phyllosilicates and rare amphibolites. Calcite is present as rounded limestone particles and as crushed angular fragments. The mortar has a very 
dense microstructure. No traces of hydraulic compounds, such as $\mathrm{C}_{2} \mathrm{~S}$ grains, were detected. Few grains of not reacted pozzolan are observed. The coarse grained binder is very rich in slag fragments, which appear as transparent angular vitreous grains and are homogeneously dispersed in the mortar. Carbonation is limited to a thin rim at the margin of the sample and along pores walls and fractures deeper in the sample, as observed for mortar MA.

Mortar MC is composed of a lime binder with a high porosity due to the presence of abundant air voids. The high visible porosity derives from the introduction of an air-entraining agent in the mortar mix. Some debonding between mortar and aggregate occurred, but cracks are generally absent in the mortar matrix.

Aggregates are poorly sorted and vary in size up to $1.5 \mathrm{~mm}$. Carbonate aggregates are dominant. No quartz aggregate is present.

The binder is coarse grained, with not reacted $\mathrm{C}_{2} \mathrm{~S}$ particles heterogeneously distributed in the matrix. A few rare $\mathrm{C}_{3} \mathrm{~S}$ grains surrounded by a clear hydration rim occur. A few pozzolan particles are present.
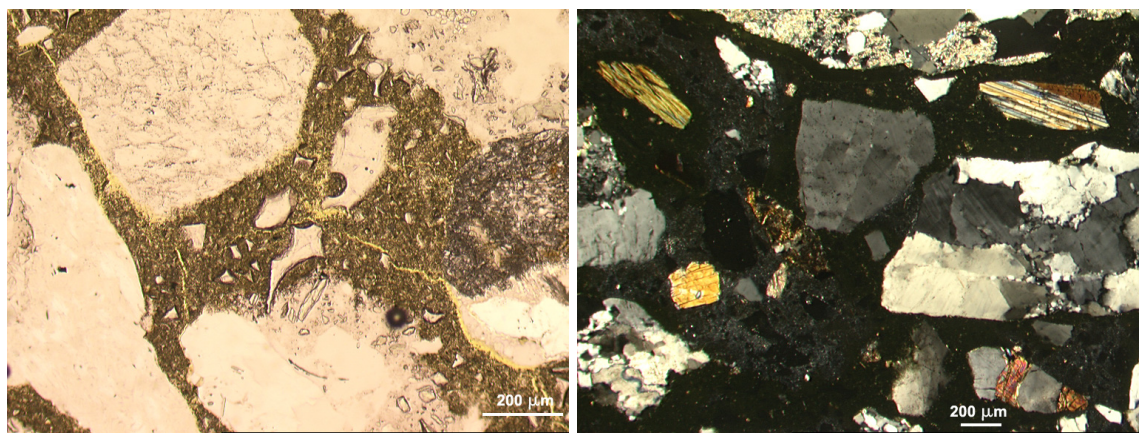

Figure 4: $\quad$ Mortar MB: slag fragments and micro-cracks in the binder matrix (left, PPL); aggregates dispersed in a dark binder matrix (right, CPL).
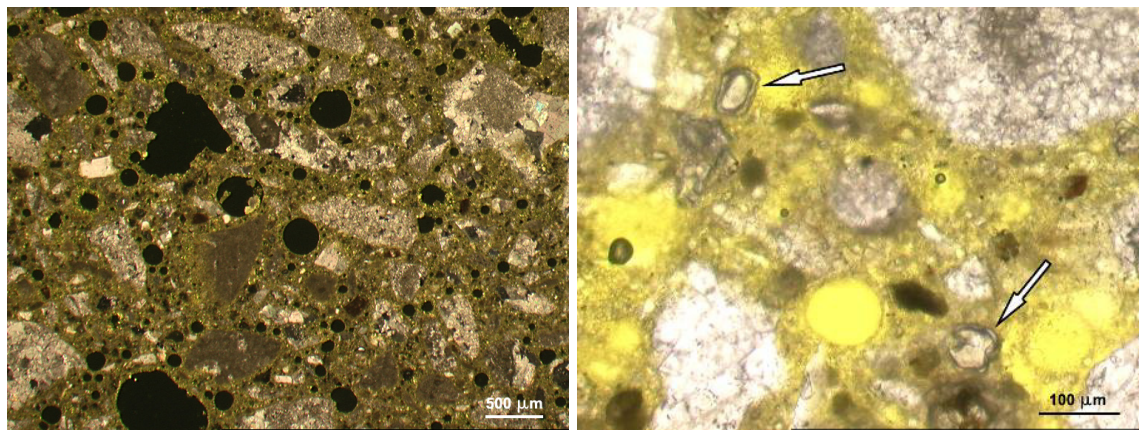

Figure 5: Mortar MC: calcite and limestone aggregate and abundant air voids (left, CPL); arrows indicate partially hydrated $\mathrm{C}_{3} \mathrm{~S}$ particles in the binder matrix (right, PPL). 

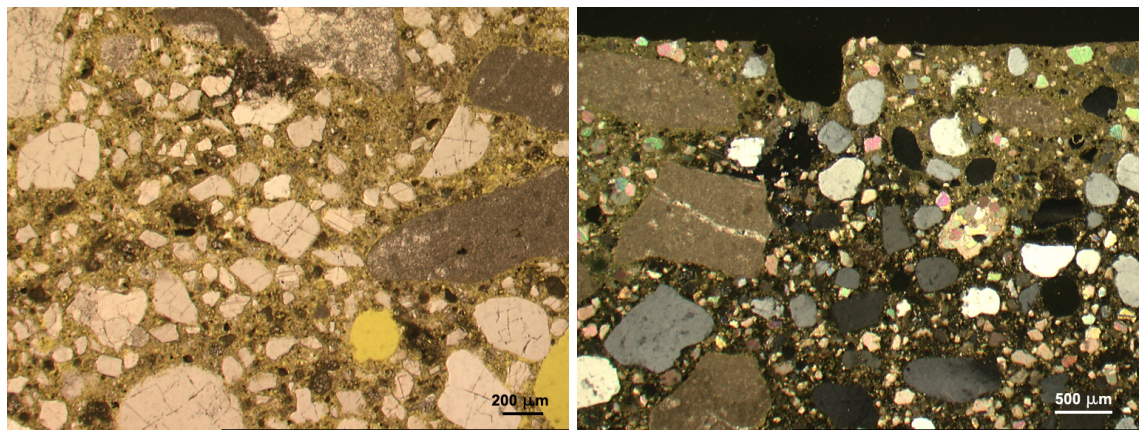

Figure 6: Mortar MD: quartz and limestone aggregates and non homogeneous distribution of $\mathrm{C}_{2} \mathrm{~S}$ particles (left, $\mathrm{PPL}$ ); carbonation front along the margin (right, $\mathrm{CPL}$ ).

Mortar MD has a hydraulic lime based binder with irregular porosity. Smaller air voids occur together with larger irregular ones. The mortar shows no microcracks.

Aggregates are poorly sorted and vary in size up to $2 \mathrm{~mm}$. Quartz, limestone and crushed angular calcite are the main aggregates; minor feldspar is also present. Limestone occurs as coarse rounded grains while the smaller aggregate fraction is composed of quartz and crushed calcite. No pozzolan grains are present.

The distribution of hydraulic phases within the binder matrix is not homogeneous and several darker zones with a higher $\mathrm{C}_{2} \mathrm{~S}$ concentration are present. A thin carbonation front proceeds from the external margins of the sample.

\subsection{SEM observation}

SEM observation of the hardened mortar samples allows the identification of the newly formed structure related to hydration process of the binder. In all examined samples hydrated calcium silicate phases (CSH) are clearly visible. They have a variable morphology. Mortar MA shows a diffuse fibrous CSH network covering most of the aggregate grains, with occasional isolated clusters of needle shaped CSH [8]. Within the CSH, some quartz grains are present and a few non reacted pozzolan particles, appearing as well defined globular grains with a smooth surface.

Mortar MB shows a denser CSH structure with elongated crystals. Slag fragments can hardly be identified as they are almost completely covered by the hydration components. No pozzolan has been detected. Ettringite formation occurred along voids and fractures. Ettringite needles appear as elongated acicular crystals.

Sample MC and sample MD have a similar microstructure. Globular CSH are cross-cut by a number of acicular, needle shaped crystals. Some isolated clusters of hydrated particles occur (fig. 7). A significant amount of portlandite crystals, 


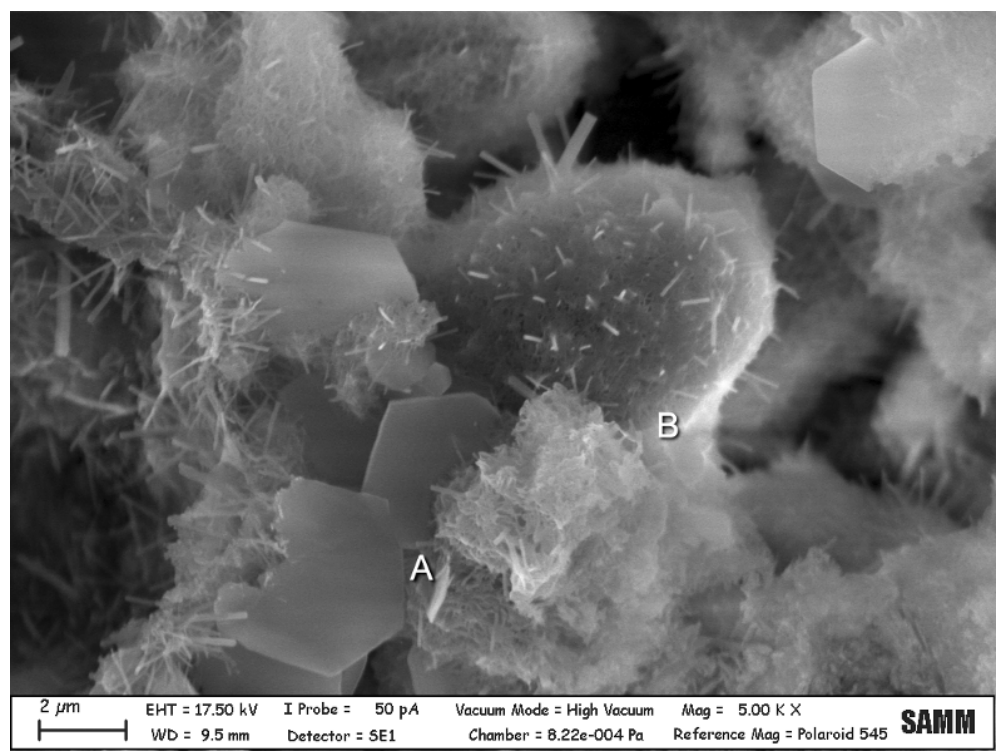

Figure 7: Detail of microstructure of mortar $\mathrm{MC}$ showing hexagonal portlandite crystals (A) and CSH particles (B).

occurring as typical hexagonal plates, are embedded within the binder matrix. No ettringite is observed in these mortars.

\subsection{Mechanical test}

The average compressive strength values after 60 days curing vary considerably, as well as the mechanical behaviour of the mortars (fig. 8). Mortar MA, containing portlandite and carbonate aggregate, and mortar MB show the highest compressive strengths, those of mortars MC and MD being lower.

As might be expected for NHL mortars, compressive strengths show a considerable increase between 28 and 60 days curing [9].

At 28 days curing, all mortars show a compressive strength in accordance to their strength resistance class reported in the technical data sheets. Mortar MD is the only one having an average compressive strength significantly lower than expected for the class it belongs to. MD shows indeed the lowest compressive strength among all the tested mortars after 28 days curing.

\section{Conclusions}

The investigation of four commercial ready-mixed mortars allows the discrimination of distinctive compositional and microstructural features of the tested products. MA has a portlandite-rich binder with some pozzolan and limestone filler. After setting a diffused CSH network homogeneously covers the aggregates and may explain the high compressive strength after 60 days curing. 


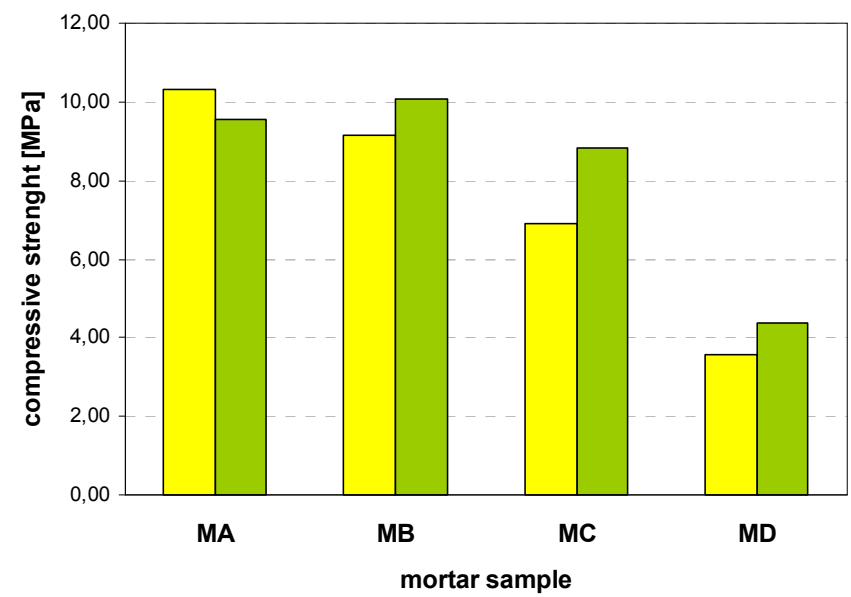

Figure 8: Average compressive strength of the mortars tested after a curing time of 28 days (left row) and 60 days (right row).

MB is, contrary to expected, a slag-lime mortar. The hydraulic behaviour of the hardened mortar is given by the slag and by the presence of pozzolan. Ettringite is formed during hydration. The hardened mortar has a compact structure and the compressive strength is comparable with that of MA.

At first glance, analysis shows that MC and MD have a rather similar composition. They both have a high amount of calcareous aggregate (mainly calcite in $\mathrm{MC}$ and dolomite in $\mathrm{MD}$ ). However, the microstructure of MC differs in one aspect, i.e. the air void content, which is probably due to the presence of an air-entraining agent in the mix. It is also the only sample clearly showing some partially hydrated $\mathrm{C}_{3} \mathrm{~S}$ grains. $\mathrm{C}_{3} \mathrm{~S}$ is uncommon in most NHL mortars. In addition, $\mathrm{MC}$ and $\mathrm{MD}$ show different compressive strengths. The high strength of $\mathrm{MC}$ with a very porous microstructure may be related to the presence of $\mathrm{C}_{3} \mathrm{~S}$.

The analytical methodology adopted for the characterization of the readymixed mortar samples proved to be useful to discriminate the products. Though they are supposed to be comparable NHL mortars, they show different compositional features, microstructures, additives and mechanical behaviour. These are essential to evaluate compatibility with historic materials and should be stated on the technical data sheets, or be determined.

Additional measurements, such as pore structure, pore size distribution and hydraulic Si amount, could be useful for a better understanding.

\section{References}

[1] UNI EN 459-1:2002. Calci da costruzione - Definizioni, specifiche e criteri di conformità. Building Lime - Definitions, specification and conformity criteria. 
[2] Allen, G., Allen, J., Elton, N., Farey, M., Holmes, S., Livesey, P. \& Radonjic, M., Hydraulic Lime Mortar for Stone, Brick and Block Masonry, Donhead: Shaftesbury, pp. 3-10, 2003.

[3] Groot, C., Ashall, G. \& Hughes, J., Characterisation of old mortars with respect to their repair. Final report of RILEM TC 167-COM, 2004.

[4] Callebaut, K., Elsen, J., Van Balen, K. \& Viaene, W., Nineteenth century hydraulic restoration mortars in the Saint Michael's Church (Leuven, Belgium) Natural hydraulic lime or cement? Cement and Concrete Research, 31, pp. 397-403, 2001.

[5] Varas, M.J., Alvarez de Buergo, M. \& Fort, R., Natural cement as the precursor of Portland cement. Cement and Concrete Research, 35, pp. $2055-$ 2065, 2005.

[6] UNI EN 1015-11:2007. Metodi di prova per opere murarie - Parte 11: Determinazione della resistenza a flessione e a compressione della malta indurita. Methods of test for mortar for masonry - Part 11: Determination of flexural and compressive strength of hardened mortar.

[7] Lanas, J. \& Alvarez, J.I., Masonry repair lime-based mortars: Factors affecting the mechanical behaviour. Cement and Concrete Research, 33, pp. 1867-1876, 2003.

[8] Diamond, S. \& Kjellsen, K.O., Resolution of fine fibrous C-S-H in backscattered SEM examination. Cement \& Concrete Composites, 28, pp. 130-132, 2006.

[9] Lanas, J., Sirera, R. \& Alvarez, J.I., Study of the mechanical behaviour of masonry repair lime-based mortars cured and exposed under different conditions. Cement and Concrete Research, 36, pp. 961-970, 2006. 